\title{
Study of the Noise and Vibration Characteristics of an Agricultural Tractor
}

\author{
Sameer Lakhani $^{1 *}$, Nirav Butani ${ }^{2}$ and Anil Kavad ${ }^{3}$ \\ ${ }^{1} I A B M, A A U$, Anand, India \\ ${ }^{2}$ CAET, AAU Godhra, India \\ ${ }^{3}$ CAET, JAU, Junagadh, India \\ *Corresponding author
}

\section{A B S T R A C T}

\section{Keywords}

Noise level, Vibration level, Tractor

\section{Article Info}

Accepted:

22 June 2020

Available Online:

10 July 2020
This study examines the vibration and noise levels produced by two different tractor engines made of different specifications such as varying horse power capacity, number of cylinders, cubic capacity of engines etc. Readings of sound level were taken at an arm's length, $10 \mathrm{~m}$ and $30 \mathrm{~m}$ from the engines and the vibration levels on tractor at different engine speeds on surfaces of different tractor components in $\mathrm{X}, \mathrm{Y}$ and $\mathrm{Z}$ directions. A digital Vibration meter VB-8201HA and digital sound level meter SL 4001 was used to measure vibration and noise levels produced by the tractors. As engine speed (RPM) increased, the noise levels also increased in all engines. The changes in the noise and vibration levels were similar during speed change from 1000 to 1500 RPM but during speed change from 1500 to 2000 RPM noise levels continued to increase while vibration levels were observed as reducing during speed change from 1500 to 2000 RPM. On bonnet of Tractor-1, maximum vibration levels recorded in velocity $(\mathrm{mm} / \mathrm{s})$ were $16.05,63.42$, 81.77 and in acceleration $(\mathrm{m} / \mathrm{s} 2), 11.03,21.23$, and 32.40 in longitudinal (X) i.e. front to rear direction at all engine speeds. On front axle on tractor-1, maximum vibrations were recorded in the vertical direction $(10.07,51.89$, and $89.29 \mathrm{~mm} / \mathrm{s})$ at engine speed of 1000 and 2000 RPM which increased with increase in engine speed of the tractor. While at 1500 RPM, maximum vibrations were observed in lateral direction (Y) i.e. side to side direction. But on front axle of tractor-2, maximum vibrations were recorded in the horizontal (longitudinal) direction $(60.78,136.36$ and $121.54 \mathrm{~mm} / \mathrm{s})$ at all engine speed. This increased with increase in engine speed of the tractor followed by lateral (side to side) vibrations at second place. On seat of the tractor, maximum vibrations were recorded in the longitudinal direction on tractor-1 followed by vibrations in vertical (top to bottom) direction at second place. On seat of the operator, maximum vibrations were recorded in the longitudinal direction on tractor-1 followed by vibrations in lateral (side to side) direction. While on the seat of the tractor-2, maximum vibrations were recorded in the longitudinal direction followed by vibrations in vertical (top to bottom) direction at second place. Noise levels in the units of dBA are recorded at ear level on both the tractors which were 89.4 and 86.3 on tractor- 1 and tractor- 2 . 


\section{Introduction}

Agricultural machinery operators are exposed to many negative influences and implications during their everyday activities on agricultural farms that can cause very complex and harmful impact on the humans. Common measuring units of vibration are Acceleration, Velocity and Displacement. Low-frequency tractor ride vibration, the resultant problem of driver discomfort and the possibility of spinal injury, Although the majority of agricultural tractors incorporate design features that attempt to reduce WBV levels experienced by the operator 1 minute to 12 hours over the frequency range in which the human body has been found to be most sensitive, namely 0.5 $\mathrm{Hz}$ to $80 \mathrm{~Hz}$. (ISO, 1997; ANSI, 2002).

In some countries, especially in the developed ones, noise levels in general environment increase dangerously. For instance, in USA, increasing in noise level is $1 \mathrm{dBA}$ per year. A research done in Ankara, the capital of Turkey, on Noise level showed that an increase of 8-10 dBA was measured within 9 years from 1970 to 1979 .The prohibition of noise is possible at three stages. Some precautions must be taken in the source of noise, in the environment that it spreads and at the target affected.

The experiment was conducted to study of the noise and vibration characteristics of an agricultural tractor" was undertaken with a view to find the existing noise and vibration levels on the agricultural tractors with specific influences of different tractor components namely the front axle, bonnet, seat, foot rest and steering wheel. The levels of noise generation were also recorded at different engine speeds of the tractor. Two tractors were selected for conducting the tests of measuring noise and vibrations at three engine speeds i.e. 1000, 1500 and 2000 RPM.

Griffin, (1998), stated that occupational exposures to whole-body vibration mainly occur in transport but also in association with some industrial processes and generally exposures to hand vibration are associated with vibration of hand-held tools and work pieces.

Celen and Arin, (2003), The noise level measured at whole agricultural measurement taken for experiment were determine over 90dBAaccpted as danger limit.

Matthews, J., (1973), stated that To maintain constant foot pressure and deterioration of visual acuity. Performing tasks that require steadiness or precision of muscular control is likely to show decrement from vibration. Points out that vibration between 3.5 and 6.0 $\mathrm{Hz}$ can have an alerting effect on subjects engaged in boring vigilance tasks.

American national standards institute [ANSI] (1988), reported that the normal human ear can hear frequencies from about $20 \mathrm{~Hz}$ to about $20,000 \mathrm{~Hz}$. It is most sensitive to sounds in the 1,000 to $4,000 \mathrm{~Hz}$ range. When measuring community response to noise, it is common to adjust the frequency content of the measured sound to correspond to the frequency sensitivity of the human ear.

Lines et al., (1995), stated that Lowfrequency vibrations, produced by the agricultural vehicles, can be extremely severe, depending upon the terrain that the agricultural vehicle is crossing and the forward speed of the vehicle. This explains why the tractor.

Parsons, (2000), stated that the sensitivity of ear is different for each frequency; the distribution of frequency must be known to examine the effects of noise. By studying the obtained frequency distribution and the sensitivity levels of ear, the noise's effects on human body can be assessed. Duration of exposure is also a consideration as well as the 
frequency content and A-weighting curve is used in practical applications denoted by $\mathrm{dB}(\mathrm{A})$ and $85-90 \mathrm{~dB}(\mathrm{~A})$ have been proposed to be the limiting values for $8 \mathrm{~h}$ exposure. Sabanci and Uz (1984), reported that the effects of noise are hidden at 30-65 dBA. Sounds at 65-85 dBA might cause physical effects beside the physiological effects. These adverse effects on autonomous nervous system can be summarized as increase in blood pressure decrease in heart pulses, getting weak in muscles and withdrawal of blood from skin. ANSI, (2002), Although the majority of agricultural tractors incorporate design features that attempt to reduce WBV levels experienced by the operator 1 minute to 12 hours over the frequency range in which the human body has been found to be most sensitive, namely $0.5 \mathrm{~Hz}$ to $80 \mathrm{~Hz}$. (ISO, 1997; ANSI, 2002).

Kumar et al., (2005), exceeded recommended Tractor noise levels (safe limits) of OSHA and NIOSH prescribed standards. TDFs had higher high frequency hearing loss than NTDFs. The mechanism of damage and prevention needs to be studied further. However, audiogram analysis showed higher prevalence of abnormalities in TDFs. TDFs (24) had more often high frequency hearing loss when compared to NTDFs (14). The noise levels observed on tractors in different operations were in the range of $90-110 \mathrm{~dB}$ (A).

Tendon and Nakra (1992) stated that vibration in the time domain can be measured through parameter such as overall RMS level, crest factor, probability density and kurtosis. Among these, kurtosis is the most effective.

\section{Materials and Methods}

Selection of tractors: Two tractors, one medium sized tractor and one mini sized (Fig. 1) from College of Agricultural Engineering and Technology (CAET) of Anand
Agricultural University (AAU) was used for the purpose of measuring their vibration levels and noise levels.

Units of vibration measurement: Measurement of vibration levels was conducted by recording velocity and acceleration in $\mathrm{mm} / \mathrm{s}$ and $\mathrm{m} / \mathrm{s} 2$ respectively.

Use of digital vibration meter: Vibration meter is used to measure the vibration levels in the units of acceleration and velocity. The Vibration meter VB-8201HA available at the FMPE laboratory was used to measure the different Vibration levels.

Vibration measurement on tractors: The vibration level observations were recorded in three directions i.e. horizontal front to rear (X) direction, horizontal side to side (Y) direction and vertical top to bottom (Z) direction (Fig. 7).

Observations were taken at different engine speeds with different vibration isolated-pad. viz 1000, 1500 and 2000 RPM at four separate locations (front axle, bonnet, seat and steering wheel) on the tractor in standstill condition.

Use of digital sound level meter: Sound level meters are used to measure the sound levels in the unit of decibels. The sound level meter SL 4001 available at the FMPE laboratory which was used to measure the different noise levels.

Measurement of noise levels: The sound level observations were recorded in decibel units.

\section{Results and Discussion}

\section{Noise and vibration levels on Tractor-1}

The graphical presentation depicts the relationship between the noise levels recorded at ear level and vibration levels measured on 
bonnet of the tractor- 1 in horizontal (side to side) direction at three different engine speeds, and assuming of any relationship of tractor boy part shown in fig. 2 and table 1 .

The graphical presentation depicts the relationship between the noise levels recorded at ear level and vibration levels measured on bonnet of the tractor in vertical direction (top to bottom) at three different engine speeds shown in table 2 and fig. 3.

\section{Noise and vibration levels on Tractor-2}

The graphical presentation depicts the relationship between the noise levels recorded at ear level and vibration levels measured on bonnet of the tractor in horizontal (side to side) direction at three different engine speeds shown in fig. 4 and table 3.
The graphical presentation depicts the relationship between the noise levels recorded at ear level and vibration levels measured on bonnet of the tractor in vertical direction at three different engine speeds shown in fig.5 and table 4.

At 1000 RPM, the average values of velocity $(\mathrm{mm} / \mathrm{s})$ in front-rear $(\mathrm{X})$ direction, side-toside (Y) direction and top-to-bottom (Z) direction are found to be 33.64, 33.21 and $17.42 \mathrm{~mm} / \mathrm{s}$ in tractor-1 Similarly tractor-2 found to be $60.78,8.9$ and $8.3 \mathrm{~mm} / \mathrm{s}$.

At 1500 RPM, the average values of velocity $(\mathrm{mm} / \mathrm{s})$ in front-rear $(\mathrm{X})$ direction, side-toside (Y) direction and top-to-bottom (Z) direction are found to be $68.35,68.88$ and $66.58 \mathrm{~mm} / \mathrm{s}$ in tractor-1 Similarly tactor-2 found to be $55.1,50.56$ and $52.88 \mathrm{~mm} / \mathrm{s}$.

Table.1 Noise and vibration levels (in horizontal direction) at different engine speeds

\begin{tabular}{|c|c|c|c|}
\hline \multirow{2}{*}{$\begin{array}{c}\text { Engine speed } \\
\text { (RPM) }\end{array}$} & \multirow{2}{*}{$\begin{array}{l}\text { Noise level at ear } \\
\text { Level (dBA) }\end{array}$} & \multicolumn{2}{|c|}{ Vibration level on tractor bonnet } \\
\hline & & $\begin{array}{l}\text { Velocity } \\
(\mathrm{mm} / \mathrm{s})\end{array}$ & $\begin{array}{l}\text { Acceleration } \\
\left(\mathrm{m} / \mathrm{s}^{2}\right)\end{array}$ \\
\hline 1000 & 80.0 & 10.28 & 7.65 \\
\hline 1500 & 83.1 & 14.98 & 9.97 \\
\hline 2000 & 89.4 & 55.10 & 21.80 \\
\hline
\end{tabular}

Table.2 Noise and vibration levels (in vertical direction) at different engine speeds on tractor bonnet

\begin{tabular}{|c|c|c|c|}
\hline \multirow{2}{*}{$\begin{array}{l}\text { Engine speed } \\
\text { (RPM) }\end{array}$} & \multirow{2}{*}{$\begin{array}{c}\text { Noise level (dBA) at } \\
\text { ear level }\end{array}$} & \multicolumn{2}{|c|}{ Vibration level on tractor bonnet } \\
\hline & & $\begin{array}{l}\text { Velocity } \\
(\mathrm{mm} / \mathrm{s})\end{array}$ & $\begin{array}{l}\text { Acceleration } \\
\left(\mathrm{m} / \mathrm{s}^{2}\right)\end{array}$ \\
\hline 1000 & 80.01 & 14.11 & 7.35 \\
\hline 1500 & 83.12 & 39.09 & 16.10 \\
\hline 2000 & 89.39 & 47.37 & 18.40 \\
\hline
\end{tabular}


Table.3 Noise and vibration levels (in horizontal direction) at different engine speeds on tractor bonnet

\begin{tabular}{|c|c|c|c|}
\hline \multirow{2}{*}{$\begin{array}{l}\text { Engine speed } \\
\text { (RPM) }\end{array}$} & \multirow{2}{*}{$\begin{array}{c}\text { Noise level } \\
\text { (dBA) at ear } \\
\text { level }\end{array}$} & \multicolumn{2}{|c|}{ Vibration level on tractor bonnet } \\
\hline & & $\begin{array}{l}\text { Velocity } \\
(\mathrm{mm} / \mathrm{s})\end{array}$ & $\begin{array}{l}\text { Acceleration } \\
\left(\mathrm{m} / \mathrm{s}^{2}\right)\end{array}$ \\
\hline 1000 & 78.61 & 33.21 & 13.40 \\
\hline 1500 & 83.26 & 68.88 & 21.09 \\
\hline 2000 & 86.28 & 50.56 & 23.70 \\
\hline
\end{tabular}

Table.4 Noise and vibration levels (in vertical direction) at different engine speeds on tractor bonnet

\begin{tabular}{|c|c|c|c|}
\hline $\begin{array}{c}\text { Engine speed } \\
\text { (RPM) }\end{array}$ & $\begin{array}{c}\text { Noise level } \\
\text { (dBA) at ear } \\
\text { level }\end{array}$ & \multicolumn{2}{|c|}{$\begin{array}{c}\text { Vibration level on tractor bonnet } \\
\text { Velocity } \\
(\mathrm{mm} / \mathrm{s})\end{array}$} \\
\hline $\mathbf{1 0 0 0}$ & 78.61 & 17.42 & $\begin{array}{c}\text { Acceleration } \\
\left(\mathrm{m} / \mathrm{s}^{2}\right)\end{array}$ \\
\hline $\mathbf{1 5 0 0}$ & 83.26 & 66.58 & 10.86 \\
\hline $\mathbf{2 0 0 0}$ & 86.28 & 52.88 & 22.29 \\
\hline
\end{tabular}

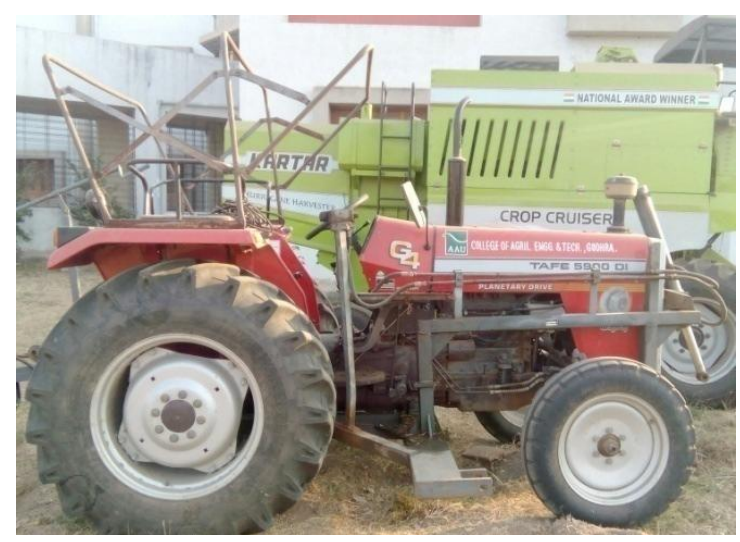

Fig. 3.1: Tractor model 5900 DI TAFE

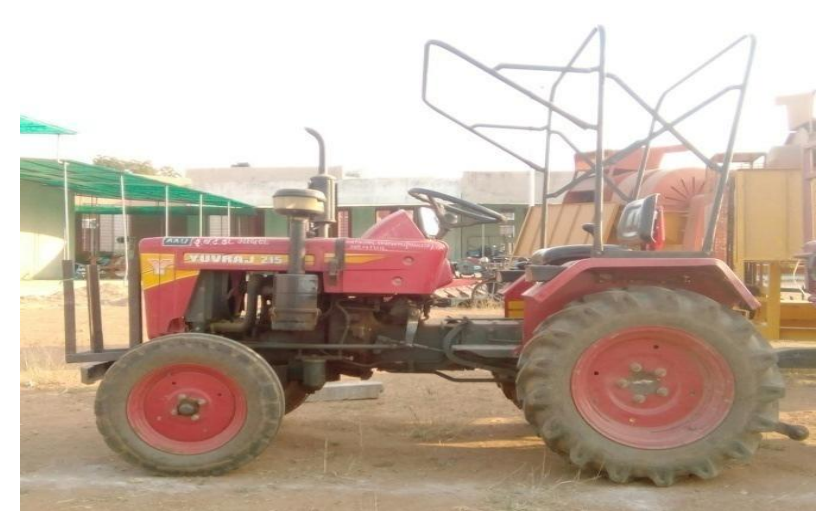

Tractor model 215 YUVRAJ

Fig.2 Noise and vibration levels (in horizontal direction) at different engine speeds on tractor-1 bonnet Noise, level (dBA) and Velocity $(\mathrm{mm} / \mathrm{s})$

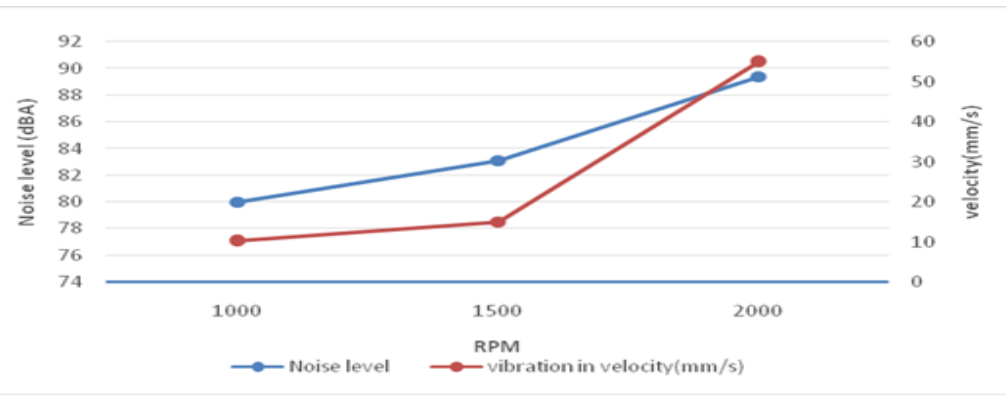


Fig.3 Noise and vibration levels (in vertical direction) at different engine speeds on tractor-1 bonnet, Noise, level (dBA) and Velocity ( $\mathrm{mm} / \mathrm{s})$

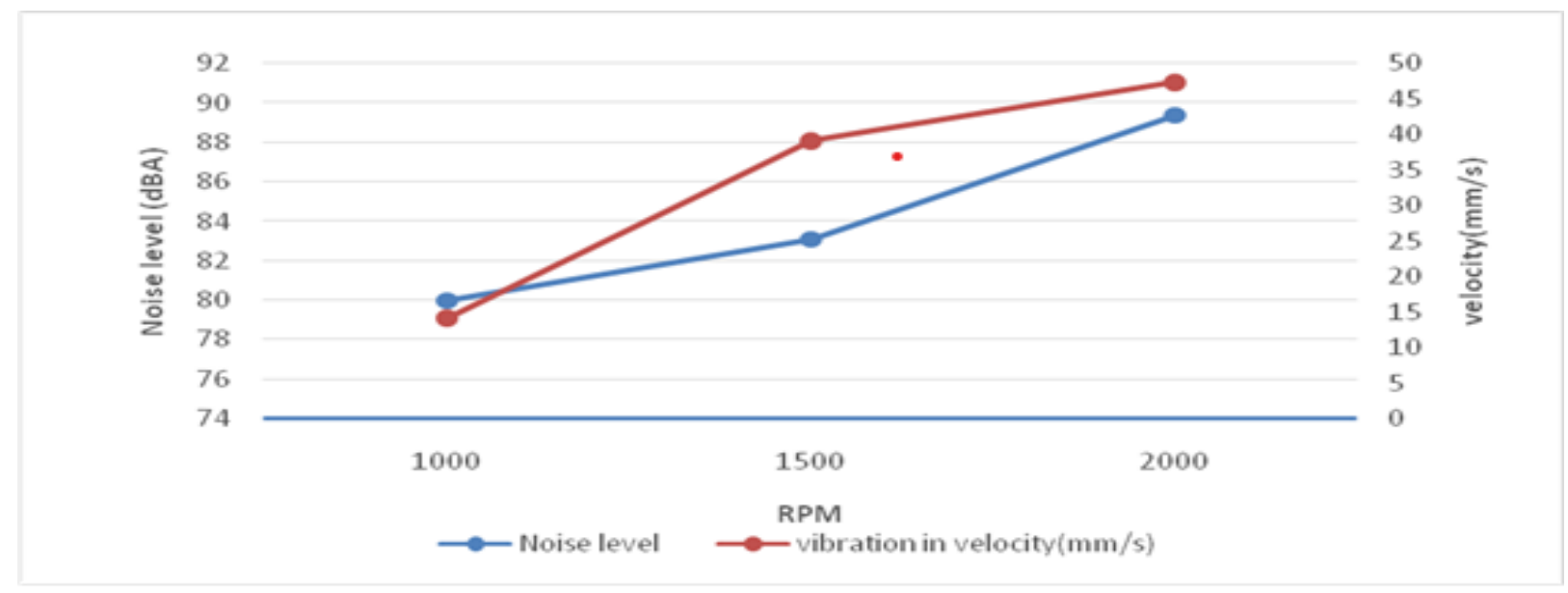

Fig.4 Noise and vibration levels (in horizontal direction) at different engine speeds on tractor-2 bonnet, Noise level (dBA) and Velocity $(\mathrm{mm} / \mathrm{s})$

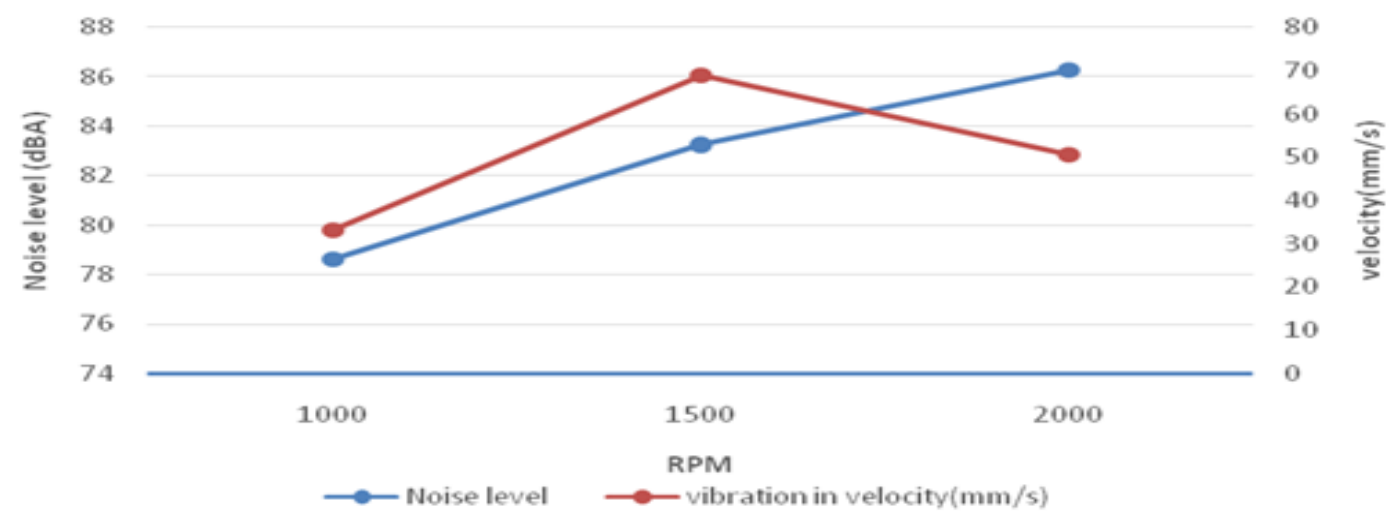

Fig.5 Noise and vibration levels (in vertical direction) at different engine speeds on tractor-2 bonnet, Noise level (dBA) and Velocity $(\mathrm{mm} / \mathrm{s})$

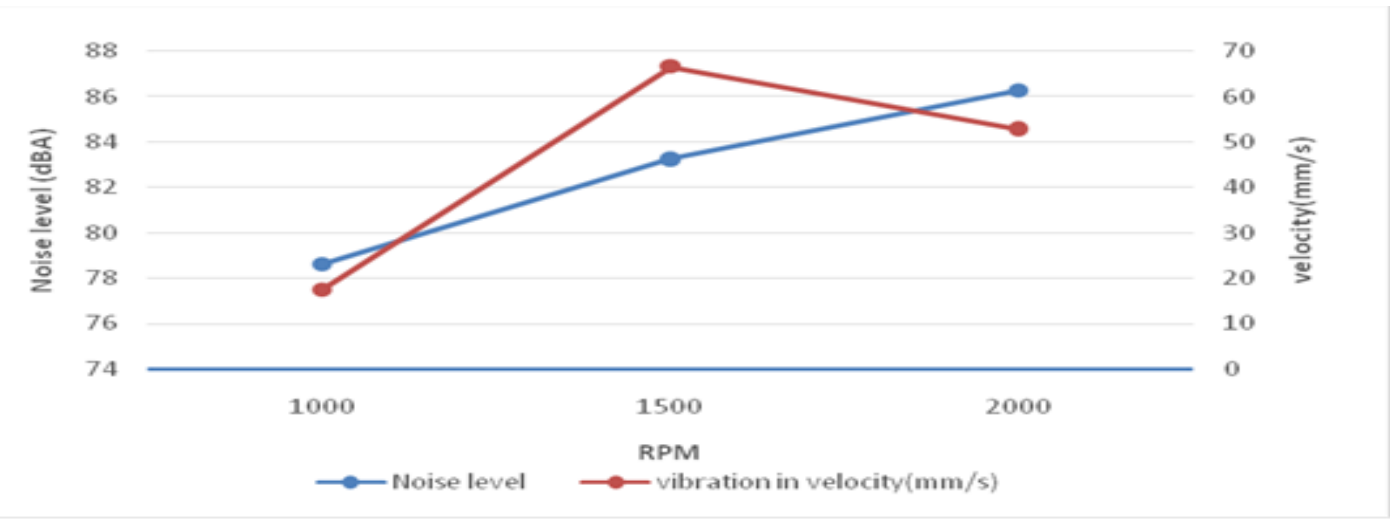


At 2000 RPM, the average values of velocity $(\mathrm{mm} / \mathrm{s})$ in front-rear $(\mathrm{X})$ direction, side-toside (Y) direction and top-to-bottom (Z) direction are found to be 55.1, 50.56 and $52.88 \mathrm{~mm} / \mathrm{s}$. $\mathrm{mm} / \mathrm{s}$ in tractor-1 Similarly tractor-2 found to be $121.54,66.81$ and 27.72 $\mathrm{mm} / \mathrm{s}$.

As anticipated, the noise levels on Tractor-1 have increased with increase in the engine speed. At 1000 RPM, the noise levels recorded at ear level, at $10 \mathrm{~m}$ and $30 \mathrm{~m}$ distance are observed as 80.0, 67.9 and 58.1 dBA. At 1500 RPM, the noise levels recorded at ear level, at $10 \mathrm{~m}$ and $30 \mathrm{~m}$ distance are observed as 83.1, 72.4 and 63.4 dBA. At 2000 RPM, the noise levels recorded at ear level, at $10 \mathrm{~m}$ and $30 \mathrm{~m}$ distance are observed as 89.4, 76.7 and $67.4 \mathrm{dBA}$. None of the noise level recorded at ear level crossed the limiting range of 85-90 dBA for $8 \mathrm{~h}$ exposure.

As expected, the noise levels on Tractor-2 have increased with increase in the engine speed. At 1000 RPM, the noise levels recorded at ear level, at $10 \mathrm{~m}$ and $30 \mathrm{~m}$ distance are observed as 78.61, 63.76 and56.78 dBA. At $1500 \mathrm{RPM}$, the noise levels recorded at ear level, at $10 \mathrm{~m}$ and $30 \mathrm{~m}$ distance are observed as 83.26, 60.92 and 63.26 dBA. At 2000 RPM, the noise levels recorded at ear level, at $10 \mathrm{~m}$ and $30 \mathrm{~m}$ distance are observed as 86.28, 71.21 and $63.26 \mathrm{dBA}$. None of the noise level recorded at ear level crossed the limiting range of 85 $90 \mathrm{~dB}(\mathrm{~A})$ for $8 \mathrm{~h}$ exposure.

\section{References}

ANSI. (1988). Quantities and Procedures for Description and Measurement of Environmental Sound, Part 1. Standard S12.9-1988.

ANSI. (1988). Quantities and Procedures for Description and Measurement of Environmental Sound, Part 1. Standard
S12.9-1988.

Clene, I. H., ann, S. (2003). Noise Levels of Agricultural Tractors Pakistan Journal of Biological Sciences 6 (19): 17061711.

Griffin, M. J. (1997). Vibration and Motion, Handbook, Human Factors and Ergonomics, A Willey-Interscience Publication John Willey \& Sons Inc, 828-857.

ISO 2002. (1990), Acoustics - Determination of occupational noise exposure and estimation of noise-induced hearing impairment. International Organization for Standardization, Geneva. 17

Kumar, A., Mathur, N. N., Varghese, M., Mohan, D., Singh, J. K. and Mahajan, P. (2005). Effect of Tractor Driving on Hearing Loss in Farmers in India AMERICAN JOURNAL OF INDUSTRIAL MEDICINE 47:341-348 (2005).

Lines, J.A., Stiles, M., Whyte, R.T. (1995). Whole Body Vibration during Tractor Driving. Journal of Low Frequency Noise and Vibration, 14(2), 87-104.

Matthews. (1973). The measurement of tractor ride comfort., SAE Paper 730795 (1973).

Parsons, K. C. (2000). Environmental ergonomics: a review of principles, methods and models. Applied Ergonomics, 31(6): 581-594.

Shoenberger, R. W. (1971). Psychophysical assessment of whole-body vibration. Human Factors 13, 41-50, S.M. Hasheminejad and Y. Mirzaei (2011), Exact3D elasticity solution for free vibrations of an eccentric hollow sphere, Journal of Sound and Vibration $330229-244$.

Tandon and Nakra. (1992). A review of vibration and acoustic measurement methods for the detection of defects in rolling element bearings. Tribology international, 32(8):469-480. 


\section{How to cite this article:}

Sameer Lakhani, Nirav Butani and Anil Kavad. 2020. Study of the Noise and Vibration Characteristics of an Agricultural Tractor. Int.J.Curr.Microbiol.App.Sci. 9(07): 3187-3194. doi: https://doi.org/10.20546/ijcmas.2020.907.372 